\title{
Comunicação
}

\section{Inspeção de distribuidores de fertilizantes sólidos na região centro sul do Estado do Paraná}

\author{
Étore Francisco Reynaldo ${ }^{1}$, Thiago Martins Machado ${ }^{2 *}$
}

$10.1590 / 0034-737 X 201663060020$

\section{RESUMO}

Os distribuidores centrífugos são máquinas indispensáveis na agricultura moderna, graças às diversas funções que podem realizar. Na maioria das vezes, porém, a regulagem e a manutenção desses equipamentos são insatisfatórias e podem trazer prejuízos, como a perda de produtividade, por problemas como a necessidade de sobreposição das passadas, ocasionada pelo déficit de fertilizantes nas fileiras de plantio. Com base nessas premissas, objetivou-se, com este trabalho, identificar os pontos críticos relacionados aos distribuidores de fertilizantes a lanço, na região centro-sul do Estado do Paraná. Para isso foi desenvolvida uma lista de verificações, com a qual, em visitas a campo, eram inspecionados os distribuidores centrífugos. As máquinas apresentaram, em 59\% das inspeções, vários problemas de manutenção e de regulagem, principalmente a do ângulo das aletas. Todos os distribuidores inspecionados foram reprovados, por apresentarem o coeficiente de variação acima dos $20 \%$. O programa de inspeção de distribuidores de fertilizantes é de grande valia e deveria ser obrigatório, nos estados de maior produção agrícola do Brasil.

Palavras chave: máquinas agrícolas; dosador gravitacional; manutenção.

\begin{abstract}
Inspection of solid fertilizer spreaders in south-central region of Paraná

Centrifugal spreaders are indispensable in modern agriculture due to several functions that they can perform. Most of the times, however, regulation and maintenance of such equipment are unsatisfactory, causing losses through lost productivity due to overlapping of past problems caused by fertilizer deficit. Based on these assumptions, the aim of the present work is to inspect and raise critical points of broadcast fertilizer spreaders in the South-central region of Paraná State. A checklist was developed, in which, through field visits, the spreaders were inspected. In 59\% of inspections, the machines had various problems of maintenance and regulation, especially regulation of the angle of the fins. All inspected spreaders failed because they presented the coefficient of variation above $20 \%$. The inspection program of fertilizer spreaders is of great value and should be mandatory in the states of increased agricultural production to avoid productivity losses due to irregularities in the spreading of fertilizers.
\end{abstract}

Key words: agricultural machines; gravity feeder; maintenance.

\footnotetext{
Submetido em 12/04/2015 e aprovado em 16/05/2016.

'Fundação Agrária de Pesquisa Agropecuária, Guarapuava, Paraná, Brasil. reynaldo@agraria.com.br

${ }^{2}$ Universidade Federal de Mato Grosso, Sinop, Mato Grosso, Brasil. tm.machado@hotmail.com

*Autor correspondente: tm.machado@hotmail.com
} 


\section{INTRODUÇÃO}

Os distribuidores centrífugos de insumos são equipamentos versáteis, destinados à aplicação de sementes, fertilizantes e corretivos. São de construção simples, de fácil regulagem e de alta capacidade operacional comparativamente a outros sistemas como, distribuidores volumétricos por queda livre, semeadoras adubadoras e cultivadores adubadores. Graças a essas características, seu uso no meio agrícola tornou-se muito popular. $\mathrm{O}$ uso correto de equipamentos distribuidores de corretivos e fertilizantes é de extrema importância para se atingirem as metas de produtividade desejadas. Na busca dessas metas, os fertilizantes são aplicados em doses determinadas para cada cultura e condição de solo (Baio et al., 2012). Entretanto, nem sempre os equipamentos aplicadores são capazes de distribuição perfeita, devido a problemas de regulagens e determinação da largura de trabalho, ocorrendo na maioria das vezes aplicações de fertilizantes com largura superior a largura efetiva de trabalho ocasionando problemas de falta de sobreposição, contribuindo para queda de produtividade nessas áreas. Não existem trabalhos que quantifiquem a queda de produtividade devido aos problemas da falta de regulagens dos distribuidores. Segundo Molin et al. (2001), os distribuidores centrífugos estão sendo utilizados como máquinas alternativas, substituindo distribuidores de fertilizantes com dosadores gravitacionais com mecanismo distribuidores por queda livre e semeadoras a lanço com sistema de distribuição pendular, tanto nas aplicações em cobertura como em aplicações pré-plantio. Na maioria dos casos, porém, não se tem informação confiável quanto à qualidade de aplicação de grande parte das máquinas disponíveis no mercado brasileiro, principalmente devido à falta de conhecimento por parte dos proprietários da maneira correta de regular o equipamento.

Ao usar esses equipamentos, é preciso observar alguns detalhes importantes para a boa prática agrícola, como a homogeneidade de distribuição e a precisão da dosagem (Brondani, 2013). Segundo Farret et al. (2008), os fatores que afetam a distância horizontal a que as partículas são lançadas são o seu tamanho, sua densidade, sua forma e a padronização e velocidade de rotação dos discos.

De acordo com Milan \& Gadanha Junior (1996), os principais parâmetros para se caracterizar o desempenho de um distribuidor centrífugo são a uniformidade de distribuição transversal, de distribuição longitudinal e de regularidade de vazão. Além desses, existem outros, como os de ergonomia, segurança e funcionalidade mecânica e caracterização ponderal e dimensional do equipamento.

Segundo Portella \& Batista (2012), no Brasil os ensaios de distribuidores de fertilizantes centrífugos são feitos da forma convencional, com o uso de bandejas para cole- ta dos produtos, que, posteriormente, são pesados em balança eletrônica.

Molin et al. (2009) analisaram as distribuições individuais dos elementos das fórmulas dos fertilizantes aplicadas por um distribuidor a lanço. Os resultados evidenciam que os fertilizantes apresentaram diferenças expressivas na sua formulação ao longo da largura de aplicação. Os mesmos autores enfatizam que as máquinas utilizadas para essas aplicações têm como característica principal grande dependência da qualidade e da condição física do produto a ser aplicado, principalmente relacionado à uniformidade granulométrica. Fica evidente que a mudança da formulação do adubo, a falta de regulagem e a falta de manutenção dos elementos que compõem o distribuidor a lanço podem causar prejuízos às lavouras por distribuição irregular dos fertilizantes durante as passadas. Em geral, o produtor rural tem dificuldade para regular adubadores a lanço e, em muitos casos, não possui coletores padronizados para determinar a largura efetiva de distribuição. Outro agravante é que, no Brasil, não existem programas de extensão para inspeção de distribuidores de fertilizantes. O que há são programas isolados em centros de pesquisas e universidades, que realizam esse tipo de serviço regionalmente, em alguns estados do Brasil. A inspeção periódica de equipamentos para aplicação de defensivos agrícolas é uma ação que visa também reduzir o impacto ambiental dessas aplicações, como parte dos programas de incentivo à qualidade ambiental, ajudando a melhorar a eficiência das aplicações (Siqueira \& Antuniassi, 2011, Dedordi et al., 2014, Alvarenga \& Cunha, 2010, Silveira et al., 2006 e Bauer et al., 2009).

Em vista dos problemas mencionados, objetivou-se, com este trabalho, identificar pontos críticos relacionados a regulagem, calibração e itens de segurança dos distribuidores centrífugos, na região centro-sul do Estado do Paraná.

\section{MATERIAL E MÉTODOS}

Este estudo foi realizado com distribuidores de fertilizantes, montados e tracionados por tratores, e as coletas de dados consistiram em visitas e entrevistas aos produtores rurais filiados à Cooperativa Agrária, localizada na colônia Vitória, distrito de Entre Rios, município de Guarapuava, PR.

Os distribuidores de fertilizantes montados avaliados foram os modelos: Tornado 1300, Twister 1500 marca Stara, Lancer 1500 marca Jan, Rota Flow 1500 marca Nogueira e de arrasto modelo Hércules 10000 marca Stara, quanto aos tratores a faixa de potência variou de 65 a $180 \mathrm{cv}$, sendo os modelos predominantes: 7630, TL 75, TL 90 marca New Holland, modelos 292, 7180 marca Massey Ferguson, modelos 6110 J, 6600 e 7180 J marca John Deere e modelos BH 180, BM 110 e A780 Valtra. 
O procedimento das inspeções consistiu em um agendamento prévio, em que o produtor era instruído a deixar o distribuidor de fertilizantes com meia carga do produto (ureia) que seria utilizado na lavoura.

Antes das avaliações dos equipamentos nas propriedades, seguia-se o padrão de escolher uma área regular, livre de buracos ou curvas de nível e com baixa declividade. O procedimento para determinação da largura efetiva de trabalho da máquina, conforme a norma ISO 5690/ 1 (ISO, 1981), consistiu com coletores padronizados, de 1 $\mathrm{m}$ de comprimento, $0,25 \mathrm{~m}$ de largura e profundidade de $0,15 \mathrm{~m}$, dispostos lado a lado, perpendicularmente à trajetória do trator na lavoura. Foram realizadas três repetições com o trator a $540 \mathrm{rpm}$ na TDP, sendo utilizada a mesma velocidade de avanço do trabalho de aplicação na lavoura. Depois de coletado o material, os coletores foram pesados e os valores inseridos no programa Adulanço 3.0 (Molin, 2009), para determinação da largura efetiva, com base em um coeficiente de variação (CV) de $20 \%$.

As avaliações foram efetuadas sempre com respeito à norma ASAE S341.3/2009 (ASABE, 2009), que estabelece os critérios para os ensaios dinâmicos. Os ensaios foram efetivados em boas condições meteorológicas, como ausência de chuva, umidade relativa do ar inferior a $80 \%$ e velocidade máxima do vento inferior a $8 \mathrm{~km} \mathrm{~h}^{-1}$.

As inspeções foram concretizadas entre os anos de 2010 e 2014. O procedimento para a coleta dos dados referentes às máquinas foi realizado com uso de um formulário específico, sendo avaliado o estado de conservação de componentes relacionados com a qualidade da distribuição, como:

- Rotação da tomada de potência (TDP): verificando-se o erro referente à rotação que o produtor utilizava na TDP do trator para o acionamento do distribuidor de fertilizantes e a recomendada pelo fabricante do distribuidor que é de 540 rpm, mensurado com tacômetro de contato digital com mira a laser, da marca Instrutherm, modelo TD-713, sendo considerados erros os que apresentassem mais de $5 \%$ de variação;

- Dimensões das aletas: verificando-se as dimensões adequadas, correspondentes ao tipo de fertilizante a ser aplicado que possibilite chegar na largura efetiva indicada pelo fabricante do equipamento;

- Rotor de distribuição: verificando-se deformações, desbalanceamentos e vibrações excessivas;

- Ângulos das aletas: verificando-se as posições ideais para a faixa de trabalho, quando CV maior que 20\%, sendo alteradas as posições até chegar à largura e ao CV estabelecidos;

- Proteção de cardan: verificando-se o funcionamento e a área coberta pelo protetor;
- Defletor: verificando-se o estado de conservação e os amassamentos, empenamentos e fixação;

- Vazamentos no mecanismo de transmissão: verificandose problemas de gotejamento, retentores com defeito, etc.;

- Aletas montadas em sentido inverso: verificando-se o sentido e a posição de montagem das aletas no rotor, sendo reprovadas as que não seguiam as recomendações do fabricante;

- Aletas diferentes nos rotores: verificando-se irregularidades de funcionamento de aletas de formas e tamanhos diferentes, quando comparados os lados direito e esquerdo;

- Agitador: verificando-se a presença e o funcionamento desse componente, nos distribuidores com mecanismo dosador gravitacional.

Durante as inspeções quando eram encontradas aletas montadas no sentido inverso, de dimensões diferentes, ou divergências nos rotores, eram feitas a substituição, a montagem e as regulagens corretas, para posterior verificação da largura efetiva.

Terminada a inspeção, recomendava-se ao agricultor que, quando mudasse a largura das passadas na lavoura ou trocasse de formulado, agendasse nova inspeção.

\section{RESULTADOS E DISCUSSÃO}

Foram realizadas 22 inspeções de distribuidores a lanço centrífugos, em oito diferentes municípios do estado do Paraná, sendo: Guarapuava, Pinhão, Guará, Palmerinha, Goioxim, Distrito Entre Rios, Jordãozinho e Cachoeira. Em $45 \%$ dos equipamentos avaliados (Tabela 1) estavam fora da rotação padrão da TDP (540 rpm), para acionamento dos distribuidores de fertilizantes. As rotações diferentes do padrão estabelecido pelas montadoras de equipamentos de distribuição de fertilizantes tinham, como consequência, os problemas de distribuição dos fertilizantes,

Tabela 1: Problemas encontrados durante as inspeções de tratores e distribuidores de fertilizantes na região centro sul do estado do Paraná

\begin{tabular}{lc}
\hline Itens avaliados & $\begin{array}{c}\text { Máquinas com } \\
\text { problemas (\%) }\end{array}$ \\
\hline Rotação da TDP & 45 \\
Agitador & 14 \\
Dimensões das aletas & 5 \\
Rotor de distribuição & 23 \\
Ângulo das aletas & 59 \\
Proteção de cardan & 32 \\
Defletor defeituoso & 9 \\
Vazamentos no mecanismo de transmissão & 14 \\
Aletas montadas em sentido inverso & 5 \\
Aletas diferentes nos rotores & 9 \\
Largura efetiva errada $(\mathrm{CV}>$ 20\%) & 100 \\
\hline
\end{tabular}

Rev. Ceres, Viçosa, v. 63, n.6, p. 893-898, nov/dez, 2016 
ocasionados pela redução da largura efetiva de trabalho. As outras consequências da rotação quando em excesso, são os danos causados à transmissão, gerando vibrações e ruídos indesejados, além de aumento do consumo de combustível. Todos os equipamentos que apresentavam vazamentos no mecanismo de transmissão estavam com rotação acima da recomendada.

Aletas com tamanhos menores do que o indicado pelo fabricante, para aplicação de determinados fertilizantes, impossibilitavam que se chegasse à largura efetiva desejada, como verificado em 5\% das inspeções. Geralmente, os distribuidores a lanço, dependendo do fabricante, vêm com duas ou mais opções de tamanho de aletas e rotores, sendo que, na maior parte das inspeções, os produtores que tinham esse problema alegavam falta de conhecimento para substituição das aletas menores por outras de maior dimensão. A montagem de aletas diferentes das originais ou de distribuidores de modelos diferentes, com dimensões (largura, altura) e peso diferentes, causa desbalanceamento do equipamento e desuniformidade na distribuição, fator encontrado em $9 \%$ das inspeções (Tabela 1). Aletas fixadas em sentido inverso ao da distribuição também causava problemas de sobreposição das passadas, como verificado em $5 \%$ das inspeções.

Em quase um quarto dos equipamentos foram constatados danos nos rotores de distribuição (Tabela 1), como amassamentos e empenamentos. Na maioria dos equipamentos, os ângulos das aletas (Figura 1) estavam fora das posições ideais para a faixa de trabalho (largura das passadas) a que estes equipamentos vinham sendo submetidos.

Em distribuidor centrífugo, na qual foi coletado o material para análise da largura efetiva desejada pelo produtor (Figura 1), foi verificado que o coeficiente de variação foi superior a $20 \%$ na distância almejada (18 m). Nas simu- lações das Figuras 2 e 3 estão simulados os tipos de trajetos possíveis e as falhas causadas pela irregularidade da distribuição, que estava ocorrendo problemas por falta de sobreposição das passadas. Foi constatada que a causa principal da irregularidade era o ângulo das aletas fora de posição correta. Analisando-se o CV (Figura 1) tanto o trajeto alternado direto e esquerdo em que o conjunto trator e distribuidor trabalharam em "vai e vem" (Figura 2) quanto no método contínuo em que fecham o talhão (Figura 3), ocorreram problemas na largura efetiva de trabalho por falta de regulagem do equipamento de forma correta,.

A falta de proteção do cardan de ligação da TDP (Tabela 1) foi observada em cerca de um terço dos equipamentos. Apesar de a maior parte dos equipamentos, (Figura 4), possuírem entre 1 e 2 anos de uso, os resultados demonstram pouca preocupação dos agricultores com segurança. Esse dado demostra valor próximo ao encontrado por Dornelles et al. (2011), que encontraram 53,6\% de casos do mesmo problema. Já Machado (2014), inspecionando máquinas para aplicação de defensivos na região de Guarapuava - PR, constatou que $76 \%$ apresentavam problemas de proteção, principalmente do cardan, item de alta periculosidade.

Quando o distribuidor a lanço apresenta mecanismo dosador gravitacional, o sistema de agitação torna-se indispensável, pois, em ocasiões em que as condições atmosféricas estiverem com umidade elevada, torna-se difícil a saída do fertilizante, para ser conduzido ao mecanismo distribuidor do equipamento. Isso acarreta problemas de paradas do equipamento, tendo-se que espalhar o fertilizante do reservatório, escavando-o com objetos pontiagudos, por causa de problemas de formação das chamadas "galerias", na massa do fertilizante, em casos extremos tem que ser paralisada a operação. A

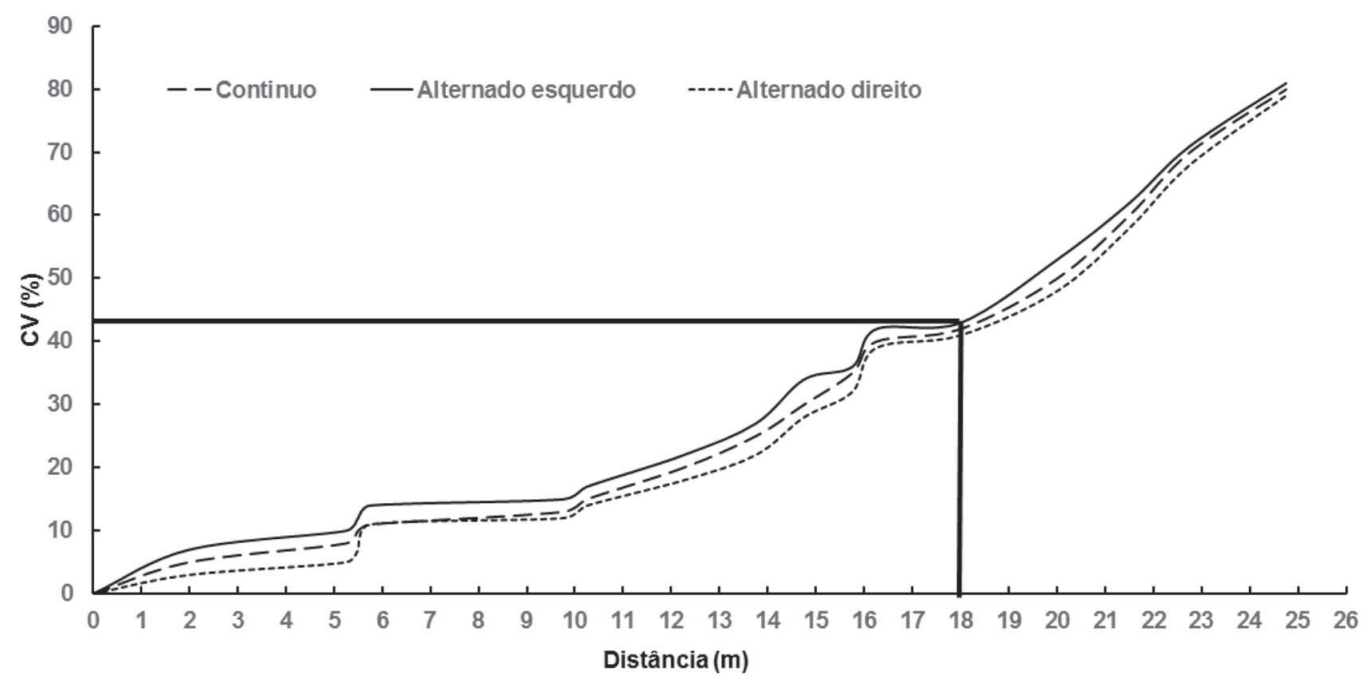

Figura 1: Largura efetiva de aplicação do distribuidor de fertilizantes em relação ao coeficiente de variação (CV), obtida pelo programa Adulanço.

Rev. Ceres, Viçosa, v. 63, n.6, p. 893-898, nov/dez, 2016 


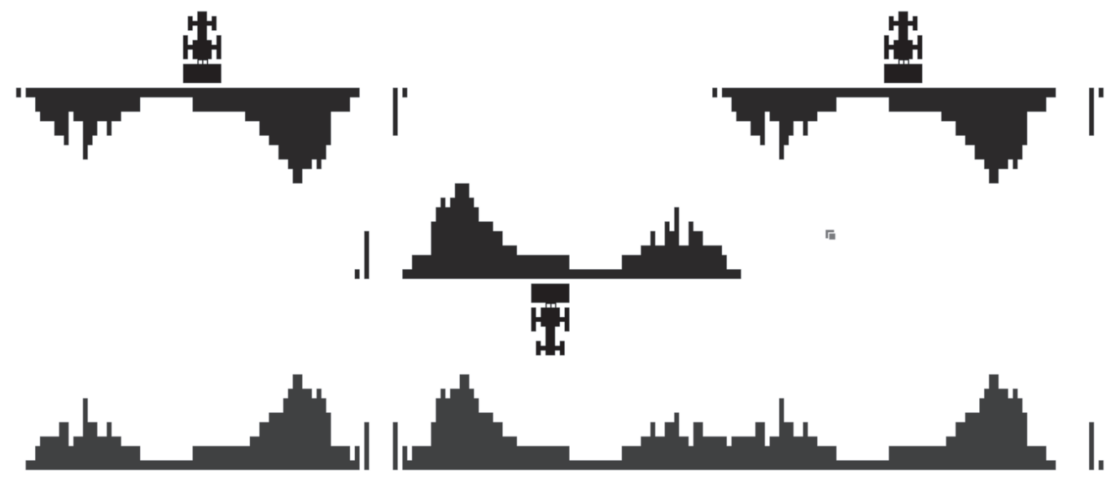

Figura 2: Distribuição de fertilizante simulada pelo programa Adulanço, para a distribuição alternada esquerda e direita (vai e vem).
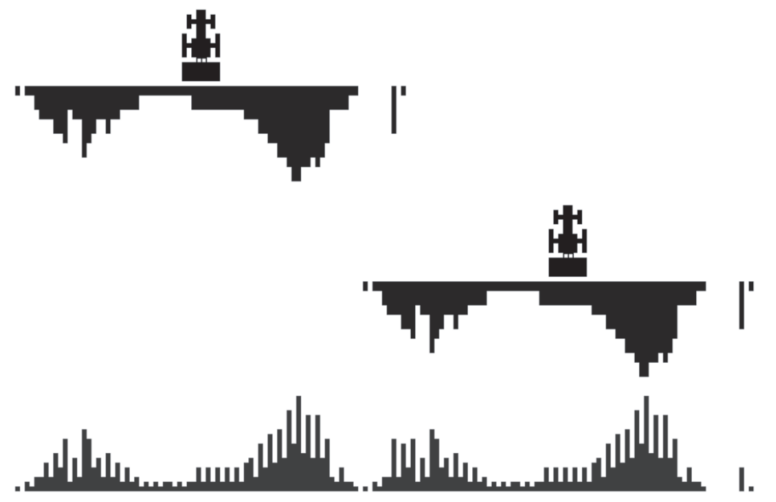

Figura 3: Distribuição de fertilizante simulada pelo programa Adulanço, para distribuição contínua em um talhão (fechamento de quadro).

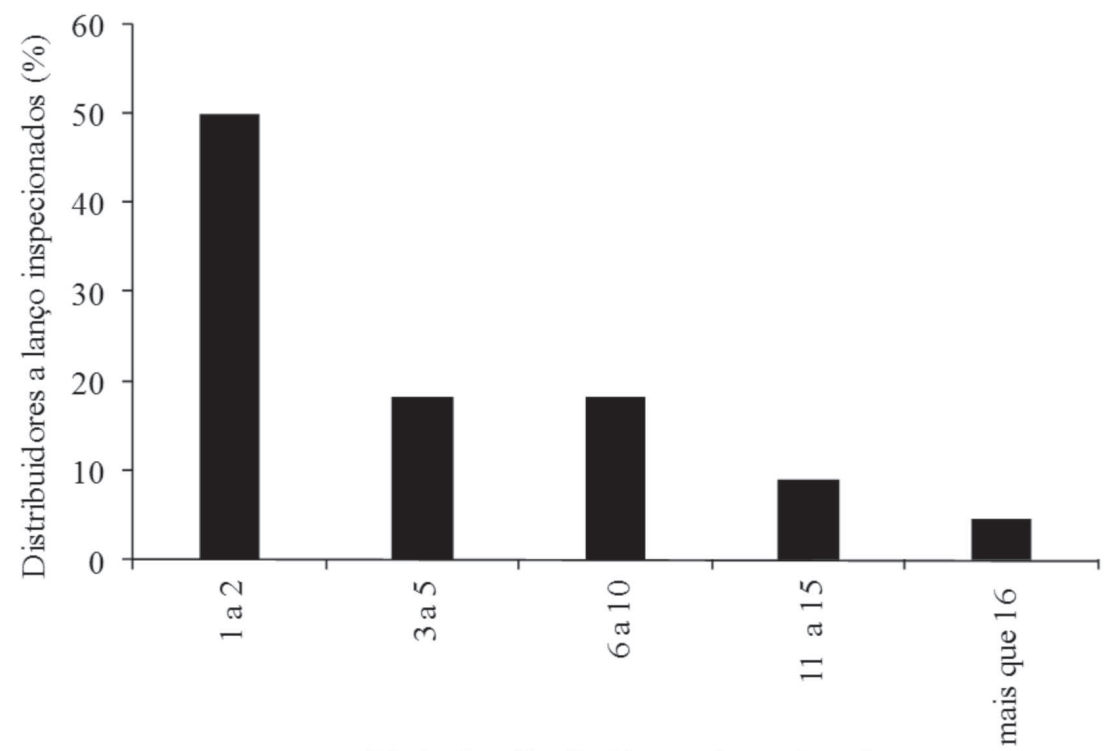

Idade dos distribuidores a lanço (anos)

Figura 4: Tempo de uso dos distribuidores a lanço centrífugos amostrados na região centro-sul do estado do Paraná.

falta do agitador ou, seu funcionamento irregular, correspondeu a parte dos problemas encontrados nas inspeções.

A maior percentagem de inspeções foi de distribuidores com mecanismo dosador gravitacional, montado no sistema dos três pontos do trator. Foi constatado, que em todas as áreas acima de 1000 hectares, os produtores uti- lizavam distribuidores com mecanismos dosador volumétrico, devido a maior capacidade do reservatório para cobrir grandes áreas.

Todas as inspeções (Tabela 1), apresentaram os valores de CV, acima dos 20\%, mostrando que a largura efetiva de distribuição de fertilizantes utilizada pelos produtores estava errada. 


\section{CONCLUSÕES}

Os pontos críticos levantados durante as inspeções mais ocorrentes foram: largura efetiva de aplicação errada e ângulo das aletas, sendo todos ocasionados por falta de conhecimento sobre regulagens do distribuidor de fertilizantes.

Há número considerável de distribuidores de fertilizantes, com falta de proteção de cardan.

O programa de inspeção de distribuidores de fertilizantes é de grande valia e deveria ser obrigatório nos estados de maior produção agrícola do Brasil.

\section{REFERÊNCIAS}

Alvarenga CB \& de Cunha JPAR da (2010) Aspectos qualitativos da avaliação de pulverizadores hidráulicos de barra na região de Uberlândia, Minas Gerais. Engenharia Agrícola, 30:555-562.

ASABE - ASAE S341.3 (2009) Procedure for measuring distribution uniformity and calibrating granular broadcast spreaders. St Joseph, ASAE Standards. 4p.

Baio FHR, Molin JM \& Leal AJF (2012) Avaliação comparativa da distribuição transversal de adubos sólidos aplicados em cobertura em culturas anuais instaladas. Bioscience Journal, 28:527536 .

Bauer FC, Pereira FDE AR, Scheeren BR \& Braga LW (2009) Diagnóstico das condições, tempo de uso e manutenção de pulverizadores no estado de Mato Grosso do Sul. Engenharia Agrícola, 29:501-507.

Brondani LB (2013) Desempenho de protótipos de disco para distribuição de ureia a lanço. Dissertação de Mestrado. Universidade Federal de Santa Maria, Santa Maria. 82p.

Dedordi GF, Modolo AJ, Carmieletto R, Dams RO, Trentin RG \& Machado F (2014) Avaliação técnica-operacional de pulverizadores de barras na região de Pato Branco - PR. Acta Iguazu, 3:144-155.

Dornelles ME, Schlosser JF, Boller W, Russini A \& Casali AL (2011) Inspeção técnica de tratores e pulverizadores utilizados em pulverização agrícola. Engenharia na Agricultura, 19:3643.

Farret IS, Schlosser JF, Durigon R, Werner V \& Knob M (2008) Variação da regulagem no perfil transversal de aplicação com distribuidores centrífugos. Ciência Rural, 38:1886-1892.

ISO - ISO 5690 (1981) Equipment for distributing fertilizers. Test methods - Part 1: full width fertilizers distributors. Geneve, ISO 5690. 12p. (Standars handbook, 13).

Machado TM (2014) Inspeção periódica de pulverizadores de barras na região de Guarapuava - PR. Enciclopédia Biosfera, $10: 1225: 1233$

Milan M \& Gadanha Jr CD (1996) Máquinas para aplicação de adubos e corretivos. In: Mialhe LG (Ed.) Máquinas Agrícolas: ensaio e certificação. Piracicaba, FEALQ. 722p.

Molin JP (2009) Adulanço 3.0: montagem do teste de campo. Manual de uso passo-a-passo - Análise de resultados. Piracicaba, USP/ESALQ. 20p.

Molin JP, Machado TM, Magalhães RP \& Faulin GDC (2009) Segregação de fertilizantes aplicados a lanço. Engenharia Agrícola, 29:614-622.
Molin JP, Menegatti LA, Pereira LL, Creminini LC \& Evangelista M (2001) Avaliação do desempenho de distribuidora de produtos sólidos a lanço em doses variáveis de uréia. In: $30^{\circ}$ Congresso Brasileiro de Engenharia Agrícola, Foz do Iguaçu. Anais, SBEA. CD ROM.

Portella JA \& Batista DG (2012) Teste eletrônico. Cultivar Máquinas, 118:12-14.

Silveira JCM, Filho AG, Pereira JO, Silva S de L \& Modolo AJ (2006) Avaliação qualitativa de pulverizadores da região de Cascavel, Estado do Paraná. Acta Scientiarum - Agronomy, 28:569573 .

Siqueira JL \& Antuniassi UR (2011) Inspeção periódica de pulverizadores nas principais regiões de produção de soja no Brasil. Revista Energia na Agricultura, 26:92-100. 